\title{
Preservação de fungos fitopatogênicos habitantes do solo
}

\author{
César J. Bueno ${ }^{1,2,}$, Márcia M. de Q. Ambrósio ${ }^{1,3}$, Nilton L. de Souza ${ }^{1,4}$
}

${ }^{1}$ Departamento de Produção Vegetal/Defesa Fitossanitária, Faculdade de Ciências Agronômicas (FCA)/UNESP, CP 237, CEP 18.603-970, Botucatu, São Paulo, Brasil; ${ }^{2}$ Bolsista de Doutorado da FAPESP; ${ }^{3}$ Bolsista de Doutorado da Capes; ${ }^{4}$ Bolsista do CNPq.

"Parte da tese de doutorado do primeiro autor.

Autor para correspondência: César Júnior Bueno.

Data de chegada:01/10/04. Aceito para publicação em: 02/05/05.

1124

\begin{abstract}
Bueno, C.J.; Ambrósio, M.M. de Q.; Souza, N.L. de. Storage of soilborne phytopathogenic fungi. Summa Phytopathologica, v.32, p. $42-50,2006$.

Preservation of soilborne phytopathogenic fungi for long periods of time is important so that researches can be followed up at any moment. Soilborne phytopathogenic fungi are organisms that can produce resistance structures in face of adverse situations, such as absence of hosts and unfavorable climatic conditions for their survival. The objective of this work was to develop preservation methodologies for resistance structures of the fungi Fusarium oxysporum f.sp. lycopersici race 2, Macrophomina phaseolina, Rhizoctonia solani AG4 HGI, Sclerotium rolfsii, Sclerotinia sclerotiorum, and Verticillium dahliae. The experiment was carried out in a randomized plots design and the method of resistance structures production was specific for each pathogen. Three treatments [room temperature

$\left(28 \pm 2^{\circ} \mathrm{C}\right)$, of refrigerator $\left(5^{\circ} \mathrm{C}\right)$ and of freezer $\left.\left(-20^{\circ} \mathrm{C}\right)\right]$ with two flasks (reps) each were assessed for each fungus. During the period of one year, survival and vigor of the pathogens were evaluated in a monthly basis. Pathogenicity tests were performed with the structures of resistance of each fungus that survived in the best treatment: a) F. oxysporum f.sp. lycopersici at refrigerator and freezer temperatures (5.2 and $2.9 \times 10^{3}$ ufc. $^{-1}$ of talc, respectively); b) M. phaseolina at refrigerator temperature [100\% of survival (S) and index 3 of vigor (V)] and $S$. rolfsii at room temperature $(74.4 \% \mathrm{~S}$ and $1 \mathrm{~V})$ and c) $S$. sclerotiorum and $V$. dahliae both at freezer temperature $(100 \% \mathrm{~S}$ and $3 \mathrm{~V})$. All, but $V$. dahliae resistance structure, remained pathogenic after one year of storage.
\end{abstract}

Additional keywords: powder talcum, sandy-organic substrate, methodologies, preservation.

\section{RESUMO}

Bueno, C.J.; Ambrósio, M.M. de Q.; Souza, N.L. de. Preservação de fungos fitopatogênicos habitantes do solo. Summa Phytopathologica, v.32, p. 42-50, 2006.

A preservação de fungos fitopatogênicos por longos períodos de tempo é importante para que pesquisas possam ser realizadas a qualquer momento. Os fungos habitantes do solo são organismos que podem produzir estruturas de resistência em face de situações adversas, tais como ausência de hospedeiros e ou condições climáticas desfavoráveis para a sua sobrevivência. O objetivo deste trabalho foi desenvolver metodologias de preservação de estruturas de resistência para os fungos Fusarium oxysporum f.sp. lycopersici raça 2, Macrophomina phaseolina, Rhizoctonia solani AG4 HGI, Sclerotium rolfsii, Sclerotinia sclerotiorum e Verticillium dahliae. O delineamento foi inteiramente casualizado, com um método de produção de estruturas para cada fungo, submetido a três tratamentos [temperatura ambiente de laboratório $\left(28 \pm 2^{\circ} \mathrm{C}\right)$, de geladeira $\left(5^{\circ} \mathrm{C}\right)$ e de freezer $\left.\left(-20^{\circ} \mathrm{C}\right)\right] \mathrm{e}$ com dois frascos por temperatura. Mensalmente, e por um período de um ano, a sobrevivência e o vigor das colônias de cada patógeno foram avaliadas em meios de cultura específicos. Testes de patogenicidade foram realizados após um ano de preservação, com as estruturas que sobreviveram aos melhores tratamentos (temperatura) para todos os fungos. As melhores temperaturas (tratamentos) para preservar os fungos foram: a) F. oxysporum f.sp. lycopersici em temperatura de refrigeração e de freezer (5,2 e $2,9 \times 10^{3} \mathrm{ufc}^{-\mathrm{g}^{-1}}$ de talco, respectivamente); b) M. phaseolina em temperatura de refrigeração [100\% de sobrevivência (S) e índice 3 de vigor (V)] e $S$. rolfsii em temperatura ambiente $(74,4 \% \mathrm{~S} \mathrm{e} 1 \mathrm{~V})$ e c) S. sclerotiorum e V. dahliae, ambos em temperatura de freezer $(100 \%$ S e $3 \mathrm{~V})$. Após um ano de preservação, somente $V$. dahliae perdeu a patogenicidade na metodologia desenvolvida.

Palavras-chave adicionais: pó de talco, substrato areno-orgânico, metodologias, preservação. 
A preservação de fungos fitopatogênicos por longos períodos de tempo é importante para que pesquisas possam ser realizadas a qualquer momento (1). No entanto, o método de preservação deve manter as características originais dos fitopatógenos, tais como capacidade de esporular e patogenicidade (1). Segundo Pimentel et al. (24), as características mencionadas têm importância na utilização para fins industriais, de ensino ou de pesquisa. Para preservar as características de esporulação e patogenicidade, Figueiredo \& Pimentel (12) relataram que os microrganismos precisam ter atividade biológica diminuída, reduzindo assim, a possibilidade de ocorrerem modificações genéticas. Os principais métodos de preservação utilizados são temperaturas baixas, nitrogênio líquido, sílica-gel, solo ou areia, tecidos secos do hospedeiro, repicagens periódicas, água destilada ou método de Castellani, liofilização e óleo mineral $(1,12)$.

Fungos fitopatogênicos habitantes do solo constituem um problema de difícil controle em uma área cultivada, pois produzem estruturas de resistência que podem sobreviver no solo por vários anos.

O presente trabalho objetivou desenvolver metodologias de preservação com as estruturas de resistência de Fusarium oxysporum f.sp. lycopersici (Sacc.) Snyder \& Hansen raça 2, Macrophomina phaseolina (Tassi), Rhizoctonia solani Kühn AG4 HGI, Sclerotium rolfsii Sacc., Sclerotinia sclerotiorum (Lib.) de Bary e Verticillium dahliae Kleb., visando facilitar a busca de alternativas de controle para esses fungos a qualquer tempo.

\section{MATERIAL E MÉTODOS}

\section{Produção de estruturas de resistência}

Fusarium oxysporum f.sp. lycopersici raça 2

De acordo com a metodologia de Blok (3) com modificações, multiplicou-se o fungo em extrato de malte líquido a $25^{\circ} \mathrm{C}$, no escuro, por sete dias. Posteriormente, colocou-se a suspensão em uma bandeja de alumínio, sem haver necessidade de centrifugação, com adição de pó de talco na proporção 2:1 (v/p). Em seguida, a bandeja foi colocada em estufa de circulação forçada de ar a $26^{\circ} \mathrm{C}$ por 14 dias, visando secar o micélio e induzir a produção de estruturas de resistência do fungo.

\section{Macrophomina phaseolina}

Utilizou-se a mesma metodologia adotada para $R$. solani, diferindo apenas na temperatura de incubação dos frascos, que foi de $32^{\circ} \mathrm{C}$.

\section{Rhizoctonia solani Kühn AG4 HGI}

Adotou-se a metodologia de Lefevre (16) para a produção de estruturas de resistência do fungo em substrato areno-orgânico.

\section{Sclerotium rolfsii}

A produção de escleródios foi efetuada com a colocação de uma estrutura do fungo sobre a superfície do meio de BDA (Batata Dextrose Ágar) + 0,05 mg. $\mathrm{mL}^{-1}$ de oxitetraciclina, incubada em BOD a $25^{\circ} \mathrm{C}$, no escuro, por 30 dias.

\section{Sclerotinia sclerotiorum}

Seguiu-se, integralmente, a metodologia de produção de estruturas de resistência do fungo em substrato feijão+fubá, descrita por Ferraz \& Café Filho (10).

\section{Verticillium dahliae}

Utilizou-se a mesma metodologia adotada para $R$. solani, diferindo no tempo e na temperatura de incubação dos frascos, que foram de 30 dias e $24^{\circ} \mathrm{C}$, respectivamente.

\section{Instalação do experimento}

$\mathrm{O}$ armazenamento das estruturas foi realizado em frasco de $500 \mathrm{~mL}$ com duas repetições por patógeno, sendo cada frasco mantido em temperatura de freezer $\left(-20^{\circ} \mathrm{C}\right)$, de geladeira $\left(5^{\circ} \mathrm{C}\right) \mathrm{e}$ em temperatura ambiente de laboratório $\left(28 \pm 2^{\circ} \mathrm{C}\right)$. Mensalmente e, pelo período de um ano, avaliou-se a sobrevivência das estruturas e o seu vigor. A avaliação da sobrevivência das estruturas dos patógenos foi feita sempre retirando amostras dos mesmos frascos submetidos às três temperaturas. Os frascos foram colocados nas três temperaturas de maneira inteiramente casualizada. Aqueles mantidos a temperatura ambiente de laboratório foram colocados no interior de armário de aço.

\section{Avaliação da sobrevivência das estruturas e o seu vigor}

\section{Fusarium oxysporum $\mathrm{f}$. sp. lycopersici raça 2}

Adotou-se a metodologia de Blok (3) modificada, que consistiu em efetuar três diluições seriadas (1:10) de uma amostra ( pó de talco+clamidósporos $=10 \mathrm{~g}$ ) coletada de cada frasco em solução salina $(0,85 \%$ de $\mathrm{NaCl})$, seguindo-se do plaqueamento de alíquotas $(0,1 \mathrm{~mL})$ sobre o meio semi-seletivo de Komada (15). As estruturas foram incubadas em estufa tipo BOD a $26^{\circ} \mathrm{C}$, no escuro, por 3-4 dias. Após a germinação das estruturas, efetuouse a contagem das unidades formadoras de colônias (ufc) por grama de material. Foram feitas quatro repetições (placas) por amostra de cada frasco e para cada uma das três diluições.

\section{Macrophomina phaseolina}

Uma amostra de $10 \mathrm{~g}$ do substrato + microescleródios foi coletada de cada frasco e cada uma foi colocada, separadamente, em uma bolsa de náilon. Cada bolsa foi submetida a desinfestação de acordo com as seguintes etapas: imersão rápida em álcool $70 \%, 20$ segundos em solução de hipoclorito de sódio a $0,5 \%$ e duas lavagens sucessivas em água destilada esterilizada. Transferiram-se porções do substrato+microescleródios para a superfície do meio semi-seletivo RB (6) modificado (39 g de BDA-batata dextrose ágar, $224 \mathrm{mg}$ i.a. de metalaxyl, $100 \mathrm{mg}$ de rifampicina e $1 \mathrm{~L}$ de água destilada). As estruturas foram incubadas em estufa tipo BOD a $32^{\circ} \mathrm{C}$, no escuro, por 4-5 dias. As porções que apresentaram colônias típicas do fungo com formação de microescleródios (cor preta) foram consideradas viáveis e contadas. Foram feitas cinco repetições (placas) por amostra de cada frasco, sendo cada placa constituída por 10 porções do substrato + microescleródios.

\section{Rhizoctonia solani AG4 HGI}

Coletou-se uma amostra de $10 \mathrm{~g}$ do substrato areno-orgânico + escleródios de cada frasco e cada uma foi colocada, separadamente, em uma bolsa de náilon. Em seguida, estas amostras foram submetidas à seguinte desinfestação superficial: imersão rápida em álcool $70 \%$, cinco segundos em solução de hipoclorito de sódio a $1 \%$ e duas lavagens sucessivas em água destilada esterilizada. As porções do substrato+escleródios desinfestadas foram transferidas para a superfície do meio semi-seletivo de KHMP (14). As estruturas foram incubadas em estufa tipo BOD a $26^{\circ} \mathrm{C}$, 
no escuro, por 3-4 dias. As porções que apresentaram hifas típicas do patógeno foram consideradas viáveis e contadas. As hifas do patógeno foram coradas com lactofenol e avaliadas sob microscópio estereoscópico. Foram feitas cinco repetições (placas) por amostra de cada frasco, sendo cada placa constituída por 10 porções do substrato+escleródios.

\section{Sclerotium rolfsii}

Uma amostra de escleródios foi coletada de cada frasco e cada uma foi colocada, separadamente, em uma bolsa de náilon. As bolsas foram submetidas à desinfestação superficial de acordo com a metodologia de Resende \& Zambolim (27) para Sclerotium cepivorum modificada: imersão rápida em álcool $70 \%$, um minuto em solução de hipoclorito de sódio a 1,5\% e duas lavagens sucessivas em água destilada esterilizada. Os escleródios desinfestados foram transferidos para a superfície do meio de BDA $+0,05 \mathrm{mg} \cdot \mathrm{mL}^{-1}$ de oxitetraciclina. As estruturas foram incubadas em estufa tipo BOD a $26^{\circ} \mathrm{C}$, no escuro, por 3-4 dias. Os escleródios que germinaram e que apresentaram hifas típicas do patógeno foram considerados viáveis e contados. Foram feitas cinco repetições (placas) por amostra de cada frasco, sendo que cada placa continha 10 escleródios.

\section{Sclerotinia sclerotiorum}

Coletou-se uma amostra de escleródios de cada frasco e cada amostra foi colocada, separadamente, em uma peneira com malha de $1 \mathrm{~mm}$ seguido de uma lavagem com jato de água de torneira por cinco minutos. Os escleródios lavados foram transferidos, separadamente, para uma bolsa de náilon e desinfestados superficialmente através dos seguintes procedimentos: um minuto em álcool $50 \%$ e três minutos em solução de hipoclorito de sódio a $1 \%$ (21). Após desinfestação, as estruturas de resistência foram transferidas para a superfície do meio de Neon $(21,29)$ e incubadas em uma estufa tipo BOD a $18^{\circ} \mathrm{C}$, no escuro, por até seis dias. A viabilidade dos escleródios foi constatada pela mudança da cor do meio de azul para amarelo claro (21). Foram feitas cinco repetições (placas) por amostra de cada frasco, sendo cada placa constituída por cinco escleródios.

\section{Verticillium dahliae}

Uma amostra de $10 \mathrm{~g}$ do substrato+microescleródios foi coletada de cada frasco e cada uma foi colocada, separadamente, em uma bolsa de náilon. Cada bolsa foi mergulhada em água destilada esterilizada, visando umedecer o substrato e facilitar a transferência de porções para a superfície do meio semi-seletivo de Ausher et al. (2). As estruturas foram incubadas, inicialmente, em estufa tipo BOD a $18^{\circ} \mathrm{C}$, no escuro, por 3-4 dias. A avaliação inicial consistiu na contagem de porções de substrato + microescleródios que apresentaram hifas típicas do patógeno. Em segui$\mathrm{da}$, as placas foram recolocadas em estufa tipo BOD a $18^{\circ} \mathrm{C}$, no escuro, por até 30 dias. Nesse período, ocorreu a formação de microescleródios do fungo em torno das colônias (cor preta), o que permitiu uma aferição da avaliação inicial. Foram feitas cinco repetições (placas) por amostra de cada frasco, sendo cada placa constituída por 10 porções do substrato + microescleródios.

As colônias desenvolvidas a partir das estruturas foram avaliadas quanto ao vigor de acordo com a seguinte escala de notas:

0 - ausência de germinação;

1 - germinação de algumas estruturas;
2 - germinação de todas as estruturas com micélio pouco vigoroso;

3 - germinação de todas as estruturas com micélio vigoroso, mantendo as características de esporulação e de aparecimento de novas estruturas de resistência.

\section{Teste de patogenicidade}

Após um ano de avaliação, realizou-se o teste de patogenicidade com as estruturas de cada espécie fúngica, que sobreviveram ao melhor tratamento (temperatura). Efetuou-se o reisolamento do patógeno das plantas de cada tratamento para completar o Postulado de Kock.

Fusarium oxysporum f.sp. lycopersici raça 2

O fungo, preservado no melhor tratamento, foi recuperado em meio de BDA+oxitetraciclina. Em seguida, colônias do fungo foram repicadas para o meio líquido de Tochinai e incubadas a $28^{\circ} \mathrm{C}$ por cinco dias (23). Adotou-se a metodologia de inoculação do patógeno em mudas de tomate da cultivar Kada, com 21 dias de idade, descrita por Pavan \& Kurozawa (23). O delineamento foi inteiramente casualizado, com três tratamentos (geladeira, freezer e testemunha) e com cinco repetições. A parcela (repetição) foi constituída por um vaso contendo três plantas. $\mathrm{O}$ tratamento testemunha consistiu na imersão de raízes de plantas em água destilada. As plantas foram mantidas a temperatura de $28^{\circ} \mathrm{C}$, com fotoperíodo de 12 horas de luz e 12 horas de escuro e em condições de estufa tipo BOD. Após 25 dias da inoculação, as plantas foram avaliadas de acordo com a escala de notas descrita por Cerezini (5).

\section{Macrophomina phaseolina}

O fungo, preservado no melhor tratamento, foi recuperado em meio RB modificado. Em seguida, colônias do fungo foram repicadas para placas de Petri contendo palitos de madeira (tipo "palitos de dente") inseridos em meio de BDA. Adotou-se a metodologia de inoculação do patógeno em plantas de feijão da cultivar Carioquinha, com formação da primeira folha verdadeira, descrita por Coelho Netto \& Dhingra (7). O delineamento foi inteiramente casualizado, com dois tratamentos (geladeira e testemunha) e com cinco repetições. A parcela (repetição) foi constituída por um vaso contendo três plantas. $\mathrm{O}$ tratamento testemunha consistiu de plantas inoculadas com palitos não colonizados pelo fungo. As plantas foram mantidas a temperatura de $30^{\circ} \mathrm{C}$, com fotoperíodo de 12 horas de luz e 12 horas de escuro e em condições de estufa tipo BOD. Após seis dias da inoculação, as plantas foram avaliadas de acordo com a escala de notas descrita por Coelho Neto \& Dhingra (7).

\section{Sclerotium rolfsii}

Os escleródios do fungo, preservados no melhor tratamento, foram recuperados em meio de BDA+oxitetraciclina. Seguiu-se a metodologia de inoculação do fungo descrita por Matsumoto et al. (18). O delineamento empregado foi inteiramente casualizado, com dois tratamentos (ambiente e testemunha) e cinco repetições. A parcela (repetição) foi constituída por um vaso contendo três sementes com dois escleródios cada. O tratamento testemunha consistiu de vasos com sementes mas sem escleródios. As plantas foram mantidas a temperatura de $28^{\circ} \mathrm{C}$, com fotoperíodo de 12 horas de luz e 12 horas de escuro e em condições de estufa tipo BOD. As plantas foram avaliadas de acordo com a escala de 
notas descrita por Matsumoto et al. (18).

\section{Sclerotinia sclerotiorum}

Os escleródios do fungo, preservados no melhor tratamento, foram recuperados em meio de Neon. Seguiu-se a metodologia de inoculação do fungo descrita por Ferraz (9) em plantas de feijão da cultivar Carioquinha com formação da primeira folha verdadeira. O delineamento empregado foi inteiramente casualizado, dois tratamentos (freezer e testemunha) e cinco repetições. A parcela (repetição) foi constituída por um vaso contendo três plantas. $\mathrm{O}$ tratamento testemunha consistiu de plantas inoculadas com palitos de madeira não colonizados pelo fungo. As plantas foram mantidas dentro de estufa tipo BOD a $26^{\circ} \mathrm{C}$, em condições de câmara úmida, por 72 horas. As plantas foram avaliadas quanto à extensão da lesão escura $(\mathrm{cm})$ a partir do ponto de inoculação.

\section{Verticillium dahliae}

O fungo, preservado no melhor tratamento, foi recuperado em meio seletivo de Ausher et al. (2). Em seguida, colônias do fungo foram repicadas para o meio de BDA e incubadas em estufa tipo BOD, a temperatura de $24^{\circ} \mathrm{C}$, por cinco dias. Seguiu-se a metodologia de inoculação do patógeno descrita por Cerezine (5) em mudas de tomate da cultivar Kada com 15 dias de idade. O delineamento empregado foi inteiramente casualizado, com dois tratamentos (freezer e testemunha) e cinco repetições. A parcela (repetição) foi constituída por um vaso contendo três plantas. O tratamento testemunha consistiu na imersão de raízes podadas de plantas em água destilada por 15 minutos. As plantas foram mantidas a temperatura de $24^{\circ} \mathrm{C}$, com fotoperíodo de 10 horas de luz e 14 horas de escuro e em condições de estufa tipo BOD. As plantas foram avaliadas 30 dias após a inoculação, de acordo com a escala de notas descrita por Cerezine (5).

\section{Análise estatística dos dados de sobrevivência e vigor das colônias dos fungos}

Em relação à freqüência total de sobrevivência dos fungos, utilizou-se o teste de Goodman (13) para contrastes entre e dentro de populações multinomiais [no caso binomiais, sendo considerado como sucesso, a presença (vivo), e fracasso, a ausência (morto)]. A avaliação do número de colônias (Fusarium) foi feita pela análise não-paramétrica de Kruskall-Wallis e complementada com as comparações múltiplas (28). A análise dos dados do vigor das colônias foi realizada também pela técnica não-paramétrica de Kruskal-Wallis e complementada com as comparações múltiplas entre pares de ambientes (22). Todas as comparações foram realizadas a nível de 5\% de significância.

\section{RESULTADOS E DISCUSSÃO}

\section{Fusarium oxysporum f.sp. lycopersici raça 2}

As melhores condições para preservar clamidósporos de $F$. oxysporum f. sp. lycopersici raça 2, em pó de talco, foram as temperaturas de geladeira e de freezer (Tabela 1). A manutenção do fungo em temperatura ambiente não foi eficaz, pois após quinze dias de avaliação, todos os clamidósporos morreram (Tabela 1).

Constatou-se durante o experimento, uma oscilação no número médio de clamidósporos viáveis do fungo nas condições de temperatura de geladeira e de freezer (Tabela 1). Uma hipótese para explicar essa oscilação, pode ser a ativação gradual de uma proteína nas estruturas de resistência provocada por situações de estresse ambiental (11). Situações de estresse ambiental ocorreram na manutenção dos clamidósporos do fungo na temperatura de geladeira e de freezer do presente trabalho. A proteína ativada torna o fungo mais resistente e garante a sua sobrevivência.

Windels (30) citou que a liofilização é o melhor método de preservação de diferentes espécies de Fusarium por longos períodos de tempo. Na liofilização do patógeno ou de suas estruturas ocorre perda de água, permitindo o armazenamento na ausência de oxigênio e vapor de água (8).

Dhingra \& Sinclair (8) relataram a preservação de Fusarium por longos períodos de tempo pelos métodos de Castellani e em solo. Os mesmos autores também constataram a manutenção de várias espécies do fungo por cinco anos pelo método de sílica-gel a temperatura de $5^{\circ} \mathrm{C}$. Este relato corrobora com os dados do presente trabalho quanto a preservação do fungo em temperatura de geladeira.

O método de preservação em óleo mineral não é muito indicado para Fusarium (8). Windels (30) não recomenda a manutenção de culturas do fungo em solo esterilizado ou em BDA, devido à perda de patogenicidade.

Tabela 1. Sobrevivência de clamidósporos de Fusarium oxysporum f.sp. lycopersici raça 2, com as estruturas submetidas a três condições de temperatura (tratamentos) e avaliação desse parâmetro durante um ano.

\begin{tabular}{|c|c|c|c|c|c|c|c|c|c|c|c|c|c|c|c|}
\hline \multirow[t]{2}{*}{ Tratamentos } & \multicolumn{14}{|c|}{ Períodos avaliados (os dois primeiros em dias e depois mensalmente) } & \multirow[t]{2}{*}{ Análise estatística } \\
\hline & \multicolumn{14}{|c|}{$\%$ média de unidades formadoras de colônia (ufc). $\mathrm{g}^{-1}$ talco } & \\
\hline Ambiente & 3375 & 462 & 0 & 0 & 0 & 0 & 0 & 0 & 0 & 0 & 0 & 0 & 0 & 0 & $0^{1}\left(0^{2} ; 27.000\right) b^{3}$ \\
\hline Geladeira & 3375 & 4462 & 8350 & 9450 & 12375 & 2850 & 4075 & 6525 & 3387 & 3075 & 2600 & 5200 & 5125 & 2950 & $34.150(20.000 ; 98.000) \mathrm{a}$ \\
\hline
\end{tabular}

${ }^{1}$ Mediana do número de colônias/g de talco do fungo;

${ }^{2}$ Semi-amplitude interquartílica com valores mínimo e máximo do número de colônias/g de talco do fungo;

${ }^{3}$ Comparações entre tratamentos. 


\section{Macrophomina phaseolina}

A melhor temperatura para manter a viabilidade dos microescleródios de M. phaseolina, produzidos e armazenados na forma de substrato areno-orgânico, foi a de geladeira (Tabela 2).

Mihail (20) citou que microescleródios de M. phaseolina produzidos sobre palito de madeira e mantidos em temperatura ambiente podem ser assim preservados por cinco anos ou mais. Ainda segundo o mesmo autor, pode-se armazenar isolados do patógeno no método de congelamento $\left(-70^{\circ} \mathrm{C}\right)$.

No presente trabalho, os dados da temperatura de freezer ($20^{\circ} \mathrm{C}$ ) mostraram que o isolado de M. phaseolina morreu após dois meses de avaliação, inviabilizando a preservação do fungo nesta condição.

\section{Rhizoctonia solani AG4 HGI}

A armazenagem de escleródios de $R$. solani, produzidos em substrato areno-orgânico, não foi promissora. Após cinco meses de avaliação, as estruturas de resistência do fungo não suportaram a preservação em nenhuma das três temperaturas testadas (Tabela 2). Não se constatou diferença significativa entre os tratamentos quanto à sobrevivência dos escleródios e o vigor das colônias (Tabela 2).

Carling \& Sumner (4) relataram que isolados de Rhizoctonia podem ser mantidos no laboratório em temperatura ambiente (20$30^{\circ} \mathrm{C}$ ) por 6-12 meses em meio PDYA (Batata dextrose levedura ágar), em placa de Petri com o meio BDA (Batata dextrose ágar), em tecidos de plantas infectados ou em solo contendo $4 \%$ de farelo de trigo.

No presente trabalho, a preservação do fungo em temperatura ambiente não confirma a citação de Carling \& Summer (4).

Culturas de Rhizoctonia não podem ser armazenadas segundo Carling \& Sumner (4) em temperatura de geladeira porque diminui a viabilidade do patógeno, o que comprova com os dados obtidos no presente trabalho (Tabela 2). Ainda segundo Carling \& Sumner (4), muitos isolados de Rhizoctonia podem ser preservados por 10 anos ou mais em grãos.

Dhingra \& Sinclair (8) relataram a preservação de culturas do fungo por alguns anos pelo método de Castellani. Esses autores descreveram também a manutenção do fungo por longos períodos de tempo no método de armazenagem em solo.

\section{Sclerotium rolfsii}

A manutenção de escleródios do fungo de forma individualizada, nas três temperaturas testadas, não foi eficiente. No entanto, as estruturas preservadas em temperatura natural de laboratório (ambiente) sobreviveram por um ano, mas com diminuição de 25,6\% da sobrevivência e índice médio de vigor 1 das colônias. Punja \& Rahe (26) relataram a armazenagem de $S$. rolfsii por longos períodos de tempo (acima de cinco anos) no método de óleo mineral, sendo as culturas do fungo mantidas neste método a temperatura ambiente.

\section{Sclerotinia sclerotiorum}

A melhor forma de preservar S. sclerotiorum foi manter os escleródios individualizados do fungo em temperatura de freezer, pois as estruturas mantiveram $100 \%$ de sobrevivência e com índice médio 3 de vigor (Tabela 2). A manutenção do fungo em temperatura ambiente não foi eficaz, pois após um mês de avaliação, todos os escleródios morreram (Tabela 2).

Pratt (25) citou que as estruturas de resistência de $S$. scleroti- orum removidas de plantas doentes ou de meios de cultura mantêm-se viáveis por longos períodos na temperatura de 2 a $5^{\circ} \mathrm{C}$. No presente trabalho, observou-se que após nove meses de avaliação (Tabela 2), ocorreu diminuição gradativa na sobrevivência do fungo na temperatura de geladeira $\left(5^{\circ} \mathrm{C}\right)$. Essa observação, permite concluir que a preservação do fungo nesta condição precisa de estudos por mais tempo para confrontar com os relatos de Pratt (25).

\section{Verticillium dahliae}

A melhor temperatura para manter os microescleródios de $V$. dahliae, produzidos e armazenados até um ano na forma de substrato areno-orgânico, foi a de freezer (Tabela 2).

Melouk (19) relatou que quando o fungo V. dahliae é multiplicado em uma mistura de solo, perlita e turfa e mantido em temperatura de $5^{\circ} \mathrm{C}$, pode ser assim preservado por cinco anos ou mais. No presente trabalho (Tabela 2), as estruturas de V. dahliae apresentaram $94 \%$ de sobrevivência quando armazenadas até um ano na temperatura de geladeira $\left(5^{\circ} \mathrm{C}\right)$ contra $100 \%$ na temperatura de freezer $\left(-20^{\circ} \mathrm{C}\right)$ e ambiente $\left(28 \pm 2^{\circ} \mathrm{C}\right)$.

Melouk (19) citou o armazenamento de muitas espécies do gênero Verticillium a temperatura de $20-30^{\circ} \mathrm{C}$ em meio BDA. Dhingra \& Sinclair (8) relataram a preservação de culturas do fungo durante alguns anos pelo método de Castellani.

\section{Teste de patogenicidade}

\section{Fusarium oxysporum f.sp. lycopersici raça 2}

As estruturas do fungo mantiveram a patogenicidade nas duas melhores temperaturas de preservação (geladeira e freezer). No entanto, quando armazenadas em temperatura de geladeira causam severidade da doença significativamente maior do que para aquelas mantidas em temperatura de freezer (Tabela 3 ).

Tabela 3. Severidade da doença causada por Fusarium oxysporum f.sp. lycopersici.

\begin{tabular}{ccc}
\hline \multicolumn{3}{c}{ Tratamentos } \\
\hline Geladeira & Freezer & Testemunha \\
\hline $88^{1, *} \mathrm{a}^{2}$ & $69 \mathrm{~b}$ & $0 \mathrm{c}$ \\
\hline
\end{tabular}

${ }^{1}$ Severidade da doença. Média de cinco repetições;

${ }^{2}$ Médias seguidas da mesma letra por tratamento não diferem estatisticamente pelo teste Tukey a $5 \%$ de probabilidade. C.V. $=9,12 \%$ e DMS $=1,01$.

"Escala de notas:

0 - plantas sadias sem sintomas externos ou internos no caule cortado na altura do primeiro internódio logo acima dos cotilédones;

20 - vasos coloridos na região do primeiro internódio sem outros sintomas visíveis;

40 - vasos coloridos até a altura da primeira folha com pelo menos um folíolo com amarelecimento;

60 - vasos coloridos até a metade do comprimento do caule, com duas ou mais folhas com amarelecimento;

80 - vasos coloridos até próximo ao ponteiro e maioria das folhas murchas com exceção do ponteiro;

100 - plantas mortas ou com vasos coloridos e folhas murchas até o ponteiro. 
Tabela 2. Sobrevivência das estruturas das espécies fúngicas Verticillium dahliae, Macrophomina phaseolina, Sclerotium rolfsii, Sclerotinia sclerotiorum e Rhizoctonia solani e vigor das colônias respectivas, com as estruturas de cada espécie submetidas a três temperaturas (tratamentos) e avaliação desses parâmetros durante um ano.

\begin{tabular}{|c|c|c|c|c|c|c|c|c|c|c|c|c|c|c|c|c|}
\hline \multirow[t]{3}{*}{ Tratamentos } & \multicolumn{14}{|c|}{ Períodos avaliados (os dois primeiros em dias e depois mensalmente) } & \multicolumn{2}{|c|}{ Análise estatística } \\
\hline & $\mathbf{0}$ & 15 & 01 & 02 & $\mathbf{0 3}$ & 04 & 05 & 06 & 07 & 08 & 09 & 10 & 11 & 12 & & \\
\hline & \multicolumn{14}{|c|}{$\%$ média de estruturas viáveis - Macrophomina phaseolina } & Vivos $^{1}$ & Mortos \\
\hline Ambiente & 100 & 100 & 100 & 100 & 100 & 100 & 96 & 98 & 100 & 100 & 100 & 98 & 100 & 100 & $99,43^{2} b^{3} ; 1392^{4}$ & $0,51 \mathrm{~b} ; 8$ \\
\hline Geladeira & 100 & 100 & 100 & 100 & 100 & 100 & 100 & 100 & 100 & 100 & 100 & 100 & 100 & 100 & $100 \mathrm{a} ; 1400$ & $0 \mathrm{a} ; 0$ \\
\hline Freezer & 100 & 100 & 97 & 14 & 0 & 0 & 0 & 0 & 0 & 0 & 0 & 0 & 0 & 0 & $22,21 \mathrm{c} ; 311$ & $77,79 \mathrm{c} ; 1089$ \\
\hline \multicolumn{17}{|c|}{ Índice médio de vigor-Macrophomina phaseolina } \\
\hline Ambiente & 3,0 & 3,0 & 2,0 & 2,0 & 2,0 & 2,0 & 1,6 & 1,8 & 2,0 & 2,0 & 2,0 & 1,8 & 2,0 & 2,0 & \multicolumn{2}{|c|}{$20^{5}\left(16-30^{6}\right) b^{3}$} \\
\hline Geladeira & 3,0 & 3,0 & 3,0 & 3,0 & 3,0 & 3,0 & 3,0 & 3,0 & 3,0 & 3,0 & 3,0 & 3,0 & 3,0 & 3,0 & \multicolumn{2}{|c|}{$30(30-30) \mathrm{a}$} \\
\hline Freezer & 3,0 & 3,0 & 1,8 & 1,0 & 0,0 & 0,0 & 0,0 & 0,0 & 0,0 & 0,0 & 0,0 & 0.0 & 0.0 & 0,0 & \multicolumn{2}{|c|}{$0(0-30) \mathrm{c}$} \\
\hline & \multicolumn{14}{|c|}{$\%$ média de estruturas viáveis - Rhizoctonia solani } & Vivos & Mortos \\
\hline Ambiente & 100 & 100 & 100 & 100 & 100 & 100 & 0 & 0 & 0 & 0 & 0 & 0 & 0 & 0 & 42,86 a; 600 & 57,14 a; 800 \\
\hline Geladeira & 100 & 100 & 100 & 100 & 100 & 100 & 34 & 0 & 0 & 0 & 0 & 0 & 0 & 0 & 45,29 a; 634 & $54,71 \mathrm{a} ; 766$ \\
\hline Freezer & 100 & 100 & 100 & 91 & 86 & 86 & 31 & 0 & 0 & 0 & 0 & 0 & 0 & 0 & 42,43 a; 594 & 57,57 a; 806 \\
\hline \multicolumn{17}{|c|}{ Índice médio de vigor - Rhizoctonia solani } \\
\hline Ambiente & 3,0 & 3,0 & 3,0 & 2,0 & 2,0 & 2,0 & 0,0 & 0,0 & 0,0 & 0,0 & 0,0 & 0,0 & 0,0 & 0,0 & \multicolumn{2}{|c|}{$0(0-30)$ a } \\
\hline Geladeira & 3,0 & 3,0 & 3,0 & 2,0 & 2,0 & 2,0 & 1,0 & 0,0 & 0,0 & 0,0 & 0,0 & 0,0 & 0,0 & 0,0 & \multicolumn{2}{|c|}{$5(0-30)$ a } \\
\hline Freezer & 3,0 & 3,0 & 2,0 & 1,2 & 1,2 & 1,2 & 1,0 & 0,0 & 0,0 & 0,0 & 0,0 & 0.0 & 0.0 & 0,0 & \multicolumn{2}{|c|}{$5(0-30) \mathrm{a}$} \\
\hline & \multicolumn{14}{|c|}{ \% média de estruturas viáveis - Sclerotium rolfsii } & Vivos & \\
\hline Ambiente & 100 & 100 & 100 & 100 & 100 & 100 & 100 & 100 & 52 & 50 & 46 & 39 & 35 & 19 & $74,36 \mathrm{a} ; 1041$ & $25,64 \mathrm{c} ; 359$ \\
\hline Geladeira & 100 & 100 & 100 & 100 & 95 & 0 & 0 & 0 & 0 & 0 & 0 & 0 & 0 & 0 & 35,36 b; 495 & 64,64 b; 905 \\
\hline Freezer & 100 & 100 & 20 & 0 & 0 & 0 & 0 & 0 & 0 & 0 & 0 & 0 & 0 & 0 & $15,71 \mathrm{c} ; 220$ & 84,29 a; 1180 \\
\hline \multicolumn{17}{|c|}{ Índice médio de vigor - Sclerotium rolfsii } \\
\hline Ambiente & 3,0 & 3,0 & 3,0 & 3,0 & 3,0 & 3,0 & 3,0 & 2,0 & 1,0 & 1,0 & 1,0 & 1,0 & 1,0 & 0,9 & \multicolumn{2}{|c|}{$25(9-30) \mathrm{a}$} \\
\hline Geladeira & 3,0 & 3,0 & 2,0 & 2,0 & 1,5 & 0,0 & 0,0 & 0,0 & 0,0 & 0,0 & 0,0 & 0,0 & 0,0 & 0,0 & \multicolumn{2}{|c|}{$0(0-30) \mathrm{b}$} \\
\hline Freezer & 3,0 & 2,0 & 1,0 & 0,0 & 0,0 & 0,0 & 0,0 & 0,0 & 0,0 & 0,0 & 0,0 & 0 & 00 & 0,0 & \multicolumn{2}{|c|}{$0(0-30) \mathrm{b}$} \\
\hline & \multicolumn{14}{|c|}{$\%$ média de estruturas viáveis - Sclerotinia sclerotiorum } & Vivos & Mortos \\
\hline Ambiente & 100 & 100 & 98 & 0 & 0 & 0 & 0 & 0 & 0 & 0 & 0 & 0 & 0 & 0 & $21,29 \mathrm{c} ; 298$ & $78,71 \mathrm{a} ; 1102$ \\
\hline Geladeira & 100 & 100 & 98 & 97 & 100 & 100 & 100 & 100 & 100 & 100 & 98 & 66 & 66 & 52 & $91,21 \mathrm{~b} ; 1277$ & $8,79 \mathrm{~b} ; 123$ \\
\hline Freezer & 100 & 100 & 100 & 100 & 100 & 100 & 100 & 100 & 100 & 100 & 100 & 10 & 10 & 96 & $99,71 \mathrm{a} ; 1396$ & $0,29 c ; 4$ \\
\hline \multicolumn{17}{|c|}{ Índice médio de vigor - Sclerotinia sclerotiorum } \\
\hline $\mathrm{Amb}$ & 3,0 & 3,0 & 1,8 & 0,0 & 0,0 & 0,0 & 0,0 & 0,0 & 0,0 & 0,0 & 0,0 & 0,0 & 0,0 & 0,0 & 0( & \\
\hline Geladeira & 3,0 & 3,0 & 2,6 & 1,8 & 2,0 & 2,0 & 2,0 & 2,0 & 2,0 & 2,0 & 1,8 & 1,4 & 1,0 & 1,0 & $20(10-$ & -30) b \\
\hline Freezer & 3,0 & 3,0 & 3,0 & 3,0 & 3,0 & 3,0 & 3,0 & 3,0 & 3,0 & 3,0 & 3,0 & 3.0 & 3.0 & 2,2 & $30(22-$ & 30) a \\
\hline & & & & $\% \mathrm{~m}$ & lia de & strutur & as viá & eis $-V$ & rticill & $\overline{m d a h}$ & & & & & Vivos & Mortos \\
\hline Ambiente & 100 & 100 & 100 & 100 & 100 & 100 & 100 & 100 & 100 & 100 & 100 & 100 & 100 & 100 & $100 \mathrm{a} ; 1400$ & $0 \mathrm{~b} ; 0$ \\
\hline Geladeira & 100 & 100 & 100 & 100 & 100 & 100 & 100 & 100 & 100 & 100 & 100 & 87 & 68 & 62 & $94,07 \mathrm{~b} ; 1317$ & 5,93 a; 83 \\
\hline Freezer & 100 & 100 & 100 & 100 & 100 & 100 & 100 & 100 & 100 & 100 & 100 & 100 & 100 & 100 & $100 \mathrm{a} ; 1400$ & $0 \mathrm{~b} ; 0$ \\
\hline & & & & & & . & & Vor & . & $\mu$ & & & & & & \\
\hline Ambiente & 3,0 & 3,0 & 3,0 & 2,0 & 2,0 & 2,0 & 2,0 & 2,0 & 2,0 & 2,0 & 2,0 & 2,0 & 2,0 & 2,0 & $20(20-$ & -30) b \\
\hline Geladeira & 3,0 & 3,0 & 3,0 & 3,0 & 3,0 & 2,0 & 2,0 & 2,0 & 2,0 & 2,0 & 2,0 & 1,2 & 1,0 & 1,0 & $20(10-$ & -30) b \\
\hline Freezer & 3,0 & 3,0 & 3,0 & 3,0 & 3,0 & 3,0 & 3,0 & 3,0 & 3,0 & 3,0 & 3,0 & 3.0 & 3,0 & 3,0 & $30(30-$ & -30) a \\
\hline
\end{tabular}

${ }^{1}$ Sobrevivência das estruturas dos fungos;

${ }^{2}$ Porcentagem de sobreviventes: vivos e mortos. Média de dez repetições;

${ }^{3}$ Comparações entre tratamentos;

${ }^{4}$ Soma das freqüências de sobreviventes (vivos e mortos) das estruturas dos fungos;

${ }^{5}$ Mediana da soma das notas do índice de vigor das colônias dos fungos;

${ }^{6}$ Semi-amplitude interquartílica com valores mínimo e máximo da soma das notas do índice de vigor das colônias dos fungos. 
Tabela 4. Severidade da doença causada por Macrophomina phaseolina.

\begin{tabular}{cc}
\hline \multicolumn{2}{c}{ Tratamentos } \\
\hline Geladeira & Testemunha \\
\hline $6^{1, *}$ & 0 \\
\hline
\end{tabular}

${ }^{1}$ Severidade da doença. Média de cinco repetições;

"Escala de notas:

1 - sem sintoma ao redor do ponto de inoculação;

2 - halo escuro ao redor do ponto de inoculação;

3 - comprimento da lesão menor que $0,5 \mathrm{~cm}$;

4 - idem ao 3 com lesão de $1 \mathrm{~cm}$;

5 - idem ao 3 com lesão entre 1 para $2 \mathrm{~cm}$;

6 - idem ao 3 com lesão entre 2 para $4 \mathrm{~cm}$;

7 - idem ao 3 com lesão entre 4 para $6 \mathrm{~cm}$ ou sem limite definido ou com pouco picnídio na base da lesão;

8 - comprimento da lesão com mais de $6 \mathrm{~cm}$ ou lesão sem limite definido com número de picnídios próximos à base do caule;

9 - caule com cor cinzenta e coberto com muitos picnídios.

Tabela 6. Severidade da doença causada por Sclerotinia sclerotiorum.

\begin{tabular}{cc}
\hline \multicolumn{3}{c}{ Tratamentos } \\
\hline Freezer & Testemunha \\
\hline $3^{1}$ & 0 \\
\hline
\end{tabular}

${ }^{1}$ Severidade da doença (extensão da lesão em $\mathrm{cm}$ ). Média de cinco repetições.

\section{Macrophomina phaseolina}

Os microescleródios de M. phaseolina podem ser preservados na forma de substrato areno-orgânico e mantidos em temperatura de geladeira por até um ano, pois as estruturas conservaram a patogenicidade (Tabela 4).

\section{Sclerotium rolfsii}

Verificou-se que apesar dos escleródios individualizados de S. rolfsii terem tido perda de $25,6 \%$ da sobrevivência após um ano em temperatura ambiente, os mesmos mantiveram a patogenicidade (Tabela 5).

\section{Sclerotinia sclerotiorum}

Observou-se que os escleródios individualizados de S. sclerotiorum, produzidos em meio de feijão+fubá e mantidos até um ano em temperatura de freezer, mantiveram a patogenicidade (Tabela 6).

Verticillium dahliae

Com base nos resultados de sobrevivência e vigor das colôni-
Tabela 5. Severidade da doença causada por Sclerotium rolfsii.

\begin{tabular}{cc} 
& Tratamentos \\
\hline Ambiente & Testemunha \\
\hline $1^{1, *}$ & 0 \\
\hline
\end{tabular}

${ }^{1}$ Severidade da doença. Média de cinco repetições;

*Escala de notas:

0 - plântulas sadias e sem sintomas de necrose no colo;

1 - plântulas com necrose do solo;

2 - tombamento de pré e pós-emergência.

Tabela 7. Severidade da doença causada por Verticillium dahliae.

\begin{tabular}{cc}
\hline \multicolumn{2}{c}{ Tratamentos } \\
\hline Freezer & Testemunha \\
\hline $11^{1, *}$ & 0 \\
\hline
\end{tabular}

${ }^{1}$ Severidade da doença. Média de cinco repetições;

"Escala de notas:

0 - plantas sadias sem sintomas externos ou internos no caule cortado na altura do primeiro internódio logo acima dos cotilédones;

20 - vasos coloridos na região do primeiro internódio sem outros sintomas visíveis;

40 - vasos coloridos até a altura da primeira folha com pelo menos um folíolo com amarelecimento;

60 - vasos coloridos até a metade do comprimento do caule, com duas ou mais folhas com amarelecimento;

80 - vasos coloridos até próximo ao ponteiro e maioria das folhas murchas com exceção do ponteiro;

100 - plantas mortas ou com vasos coloridos e folhas murchas até o ponteiro.

as de V. dahliae (Tabela 1) constatou-se que a nova metodologia desenvolvida propiciava a preservação do fungo em substrato areno-orgânico desde que mantido em temperatura de freezer. No entanto, verificou-se que a severidade da doença foi baixa (Tabela 7), o que inviabiliza essa metodologia de preservação para este fungo.

Para $R$. solani AG4 HGI não foi realizado o teste de patogenicidade, pois a metodologia de preservação desenvolvida não mostrou ser promissora (Tabela 2).

Os dados das Tabelas 1, 2, 3, 4, 5 e 6, mostram uma nova metodologia e uma nova alternativa de preservação para os fungos $F$. oxysporum f.sp. lycopersici raça $2, M$. phaseolina, S. rol$f_{\text {sii }}$ e $S$. sclerotiorum por no mínimo um ano.

As cinco espécies fúngicas inoculadas nas plantas foram reisoladas, completando assim, o postulado de Koch.

Segundo Dhingra \& Sinclair (8) não existe um método universal para armazenar patógenos de plantas. Aparecido et al. (1) mencionaram que o método de preservação deve manter as características originais dos fitopatógenos como a capacidade de esporular e a patogenicidade. 
Apesar dos dados obtidos no presente trabalho abrirem novas alternativas de preservação para $F$. oxysporum f.sp. lycopersici raça $2, M$. phaseolina, $S$. rolfsii e $S$. sclerotiorum, futuros trabalhos deverão testar esses métodos por um tempo maior de armazenagem para confirmar a eficácia de cada um. A manutenção de estruturas de resistência dos fungos do presente trabalho, assegurou a não ocorrência de modificações genéticas, pois de acordo com Figueiredo \& Pimentel (12), quanto menor a atividade biológica menor a possibilidade de ocorrerem alterações moleculares.

Trabalhos envolvendo comparação de métodos de preservação precisam avaliar, além da sobrevivência, vigor e patogenicidade dos fungos, também a severidade da doença. A manutenção dessas características é vital na busca de novas alternativas de controle.

Os métodos de preservação devem ter baixo custo e requerer pouco espaço. Estes requisitos foram contemplados nos métodos desenvolvidos para $F$. oxysporum f.sp. lycopersici raça 2, M. phaseolina, $S$. rolfsii e $S$. sclerotiorum. Há na literatura metodologias promissoras para preservar alguns destes fitopatógenos. No entanto, as mesmas requerem a aquisição de equipamentos caros e específicos, tais como no método de congelamento, nitrogênio líquido e liofilização.

Futuros trabalhos deverão desenvolver procedimentos de inoculação, utilizando os métodos de produção e preservação do presente trabalho. O desenvolvimento destes procedimentos será fundamental na realização de diversos tipos de estudos em que a regularidade de aparecimento da doença seja garantida. Dessa forma, os métodos de produção e preservação de estruturas de resistência dos fungos Fusarium, Macrophomina, Sclerotium e Sclerotinia, possibilitarão no prazo de pelo menos um ano, inóculos em quantidade e qualidade padronizados de forma que a qualquer momento poder-se-ão utilizá-los.

\section{REFERÊNCIAS BIBLIOGRÁFICAS}

1. Aparecido, C.C.; Egydio, A.P.M.; Figueiredo, M.B. Avaliação de três métodos para preservação de fungos fitopatogênicos. Summa-Phytopathologica, Jaboticabal, v.27, n.4, p.421-424, 2001.

2. Ausher, R.; Katan, J.; Ovadia, S. An improved selective medium for the isolation of Verticillium dahliae. Phytoparasitica, Rehovot, v.3, n.2, p.133-137, 1975.

3. Blok, W.J. Early decline of asparagus in the Netherlands: etiology, epidemiology and management. 1997. 177f. Phd (Thesis) - Wageningen Agricultural University, Wageningen, 1997.

4. Carling, D.E.; Sumner, D.R. Rhizoctonia. In: Singleton, L.L.; Mihail, J.D.; Rush, C.M. (Ed.). Methods for research on soilborne phytopathogenic fungi. St. Paul: The American Phytopathological Society, 1992. p.157-165.

5. Cerezine, P.C. Murcha de Verticillium em tomateiro: variabilidade do patógeno e comportamento de variedades. 1989. 80f. Dissertação (Mestrado em Agronomia/Proteção de Plantas) - Faculdade de Ciências Agronômicas, Universidade Estadual Paulista, Botucatu, 1989.

6. Cloud, G.L. Comparison of three media for enumeration of sclerotia of Macrophomina phaseolina. Plant Disease, St. Paul, v.75, n.8, p.771-772, 1991

7. Coelho Netto, R.A.; Dhingra, O.D. Method for evaluating bean genotype reaction to Macrophomina phaseolina. Fitopatologia
Brasileira, Brasília, v.21, n. 2, p.236-242, 1996.

8. Dhingra, O.D.; Sinclair, J.B. Basic plant pathology methods. 2. ed. Boca Raton: CRC Press, 1995. 434p.

9. Ferraz, L.C.L. Biologia de Sclerotinia sclerotiorum e aspectos de controle cultural de mofo-branco em feijoeiro. 1996. 202f. Dissertação (Mestrado em Agronomia/Fitopatologia) - Faculdade de Agronomia e Medicina Veterinária, Universidade de Brasília, Brasília, 1996.

10. Ferraz. L.C.L.; Café Filho, A.C. Efeito da adição de fubá no meio de produção de escleródios e outros fatores influenciando na formação de apotécios de Sclerotinia sclerotiorum. Fitopatologia Brasileira, Brasília, v.23, n.3, p.364-369, 1998.

11. Freeman, S.; Ginzburg, C.; Katan, J. Heat shock protein synthesis in propagules of Fusarium oxysporum f.sp. niveum. Phytopathology, St. Paul, v.79, n.10, p.1054-1058, 1989.

12. Figueiredo, M.B.; Pimentel, C.P.V. Métodos utilizados para conservação e fungos na micoteca da seção de micologia fitopatológica do instituto biológico. Summa Phytopathologica, Piracicaba, v.1, n.4, p. 299-302, 1975.

13. Goodman, L.A. Simultaneous confidence intervals for contrasts among multinomial populations. Annals of Mathematical Statistics, Beachwood, v.35, n.2, p.716-725, 1964.

14. Ko, W.; Hora, F.K. A selective medium for Rhizoctonia solani in soil. Phytopathology, St. Paul, v.61, n.6, p.707-710, 1971.

15. Komada, H. Development of a selective medium for quantitative isolation of Fusarium oxysporum from natural soil. Review of Plant Protection Research, Tokyo, v.8, p.114-124, 1975.

16. Lefevre, A.F.V. Determinação da temperatura letal para Rhizoctonia solani Kühn e Sclerotium rolfsii Sacc. e efeitos da solarização sobre algumas variáveis do solo. 1990. 94f. Dissertação (Mestrado em Agronomia/Proteção de Plantas) - Faculdade de Ciências Agronômicas, Universidade Estadual Paulista, Botucatu, 1990.

17. Lockwood, J.L. Curso avançado sobre fitopatógenos do solo. Piracicaba: Universidade de São Paulo, 1977. 41p.

18. Matsumoto, M.N.; Homechin, M.; Massola Jr., N.S.; Kamikoga, A.T.M. Efeito do substrato de cultivo na produção de escleródios e na patogenicidade de Sclerotium rolfsii. Summa Phytopathologica, Jaboticabal, v.26, n.1, p.91-94, 2000.

19. Melouk, H.A. Verticillium. In: Singleton, L.L.; Mihail, J.D.; Rush, C.M. (Ed). Methods for research on soilborne phytopathogenic fungi. St. Paul: The American Phytopathological Society, 1992. p.175-178.

20. Mihail, J.D. Macrophomina. In: Singleton, L.L.; Mihail, J.D.; Rush, C.M. (Ed). Methods for research on soilborne phytopathogenic fungi. St. Paul: The American Phytopathological Society, 1992. p.134-136.

21. Nasser, L.C.B.; Boland, G.J.; Sutton, J.C. Meio de cultura semi-seletivo para detecção da viabilidade dos escleródios de Sclerotinia sclerotiorum. Fitopatololgia Brasileira, Brasília, v.20, n.2, p.376, 1995. Resumo.

22. Norman, G.R.; Steiner, D.L. Biostatistics - the bare essentials. St. Louis: Mosby Boor, 260 p. 1994.

23. Pavan, M.A.; Kurozawa, C. Comportamento de algumas cultivares e progênies de tomateiro às raças 1 e 2 de Fusarium oxysporum f.sp. lycopersici (WR) Snyder \& Hansen. Summa Phytopathologica, Piracicaba, v.7, n.3/4, p.57-62, 1981.

24. Pimentel, C.P.V.; Pitta, G.B.P.; Figueiredo, M.B. Preservação da patogenicidade de alguns fungos conservados em água destilada. O Biológico, São Paulo, v.46, n.12, p.279-308, 
1980.

25. Pratt, R.G. Sclerotinia. In: Singleton, L.L.; Mihail, J.D.; Rush, C.M. (Ed). Methods for research on soilborne phytopathogenic fungi. St. Paul: The American Phytopathological Society, 1992. p.74-78.

26. Punja, Z.K.; Rahe, J.E. Sclerotium. In: Singleton, L.L.; Mihail, J.D.; Rush, C.M. (Ed). Methods for research on soilborne phytopathogenic fungi. St. Paul: The American Phytopathological Society, 1992. p.166-170.

27. Resende, M.L.V.; Zambolim. L. Eficiência de métodos utilizados para quantificação da população de escleródios de Sclerotium cepivorum Berk. no solo. Fitopatologia Brasileira,
Brasília, v.11, n.3, p.493-500, 1986.

28. Siegel, S.; Castellan Jr., N.J. Non parametric statistics for the behavioral sciences, 2. ed. New York: McGraw-Hill, 1988. 312p.

29. Steadman, J.R.; Marcinkowska, J.; Rutledge, A. Semi-selective medium for isolation of Sclerotinia sclerotiorum. Canadian Journal of Plant Pathology, Guelph, v.16, n.1, p.70, 1994.

30. Windels, C.E. Fusarium. In: Singleton, L.L.; Mihail, J.D.; Rush, C.M. (Ed). Methods for research on soilborne phytopathogenic fungi. St. Paul: The American Phytopathological Society, 1992. p.115-128. 